\title{
Crystallization behavior and morphological features of ethylene-vinyl alcohol 44 copolymer
}

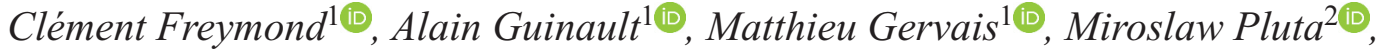 \\ Tomasz Makowski ${ }^{2 \mathbb{D}}$, Ewa Piorkowska ${ }^{2 \mathbb{D}}$, Cyrille Sollogoub ${ }^{1 * \mathbb{D}}$ \\ ${ }^{1}$ PIMM, Arts et Metiers Institute of Technology, CNRS, Cnam, HESAM University, 151 Bd. de l'Hopital, 75013 Paris, \\ France \\ ${ }^{2}$ Centre of Molecular and Macromolecular Studies, Polish Academy of Sciences, Sienkiewicza 112, 90363 Lodz, Poland
}

Received 27 July 2021; accepted in revised form 5 November 2021

\begin{abstract}
This work is a first attempt to study the crystallization behavior of ethylene-vinyl alcohol copolymer with $44 \mathrm{~mol} \%$ of ethylene units (EVOH44) and to observe the supermolecular structures developed during its crystallization. Thermal analysis has evidenced a very fast crystallization and the formation of different crystal populations during isothermal crystallization. In-situ wide-angle X-ray scattering experiments using a synchrotron radiation source have shown a unique orthorhombic morphology, independently of the crystallization conditions. Small spherulites (with an average radius of about $1 \mu \mathrm{m}$ ) were observed using polarized optical microscopy and confirmed by typical four-leaf patterns obtained by smallangle light scattering. In-situ atomic force microscopy has revealed stacked lamellae growing from common centers to form small spherulitic entities. Finally, studies of isothermal crystallization have evidenced the existence of partial crystallization (especially at high crystallization temperatures) and the need for higher undercooling to complete crystallization.
\end{abstract}

Keywords: thermal properties, crystallization, EVOH, ethylene-vinyl alcohol copolymer, crystalline morphology

\section{Introduction}

Ethylene-vinyl alcohol copolymers (EVOH) are semi-crystalline polymers widely used in food packaging industry due to their outstanding barrier properties to gases and hydrocarbons [1]. Those properties have widely been assigned on the one hand to the inherent high degree of crystallinity of those copolymers, and on the other hand, to the numerous hydrogen bonds coming from the presence of hydrox$y l$ groups, that leads to a reduction of free volume hindering the permeant diffusion [2-4]. Produced via a saponification reaction of a parent ethylene-co-vinyl acetate copolymer (EVAc), ethylene-vinyl alcohol copolymer displays an irregular succession of monomer units [5]. Despite this random structure, EVOH crystallizes irrespective of the copolymer composition $[6,7]$. Bunn and coworkers $[8,9]$ suggested that, since hydroxyl groups and hydrogen atoms are not too different in size and shape, crystallization may occur whatever their position along the chains, inducing the formation of a 'mixed crystal', as opposed to a 'pure crystal' where all crystal meshes have the exact same composition. Further investigations using thermal analysis, IR and NMR spectroscopies and X-ray diffraction confirm the fact that both ethylene and vinyl alcohol residues are incorporated into the crystalline regions of the copolymer $[6,10-13]$. Thus, the EVOH crystalline structure was found to adopt the poly(vinyl alcohol) $(\mathrm{PVOH})$ lattice (i.e., monoclinic) for low ethylene content, the polyethylene (PE) lattice (i.e., orthorhombic) for high ethylene content and an intermediate lattice (i.e., pseudo-hexagonal) for intermediate compositions. This latter can be seen as a slightly distorted 
orthorhombic lattice, in which the hydroxyl groups form 'point defect' $[8,14]$.

Cerrada et al. [15] pointed out the effect of both copolymer composition and thermal history on crystal structure. Besides, using NMR spectroscopy, VanderHart et al. [16] studied samples in the ethylene-rich composition ranges and concluded that there was no significant partitioning in $\mathrm{EVOH}$. Nevertheless, they observed rejection of some defects (ethyl and butyl branches from polymerization side reactions or acetate branches from the incomplete hydrolysis of the EVAc parent copolymer) from the crystalline zones. Franco-Urquiza and coworkers $[17,18]$, using the successive self-nucleation and annealing (SSA) technique developed by Müller et al. [19], showed the existence of a strong segregation during EVOH crystallization possibly related to the structural modifications induced by repetitive melt extrusions. In a quite comprehensive study [20], the leading role of hydrogen bonds in the crystallization process of EVOH 32 with $32 \mathrm{~mol} \%$ of ethylene units was evidenced via 2D correlation infrared spectroscopy. In particular, two different crystallization processes were identified, both dominated by the generation of hydrogen bonds: a primary crystallization (around $160^{\circ} \mathrm{C}$ ) leading to the separate crystallization of vinyl alcohol units and ethylene units; a secondary perfection process (around $100^{\circ} \mathrm{C}$ ) characterized by a local rearrangement and the formation of imperfect mixed crystals. Different strategies have been proposed to modify and tune the crystallization process of EVOH by mixing it with another polymer or additive that may interact with the numerous $-\mathrm{OH}$ groups: polymer blending [21,22], additive addition [23-25], chemical modification [26], nanocomposite preparation [27-29].

Despite a rather extensive characterization of the crystalline structure of EVOH copolymers, there is very little understanding of the crystallization mechanism and behavior of these copolymers. In particular, no data are available in the literature concerning the supermolecular structures developed during EVOH crystallization, still an inherent feature of the morphology of crystalline polymers. In the aim of gaining more understanding on the crystallization behavior of EVOH, an EVOH44 which does not exhibit polymorphic behavior. was chosen for this study. Thermal analysis in conjunction with real-time wideangle X-ray scattering (WAXS) at a synchrotron radiation source, were performed. Basic morphologies of bulk melt-crystallized EVOH44 were also observed using different characterization techniques: polarized optical microscopy (POM), small-angle light scattering (SALS), atomic force microscopy (AFM), and small angle X-ray scattering (SAXS).

\section{Materials and methods}

\subsection{Materials}

Ethylene vinyl-alcohol (EVOH) E171B with $44 \mathrm{~mol} \%$ of ethylene unit (EVOH44) was supplied by Kuraray. Low density polyethylene (LDPE) 2426F was supplied by PTT Global Chemical.

\subsection{Preparation of EVOH44 film}

An EVOH44 film was prepared by extrusion from pellets that have been dried for $24 \mathrm{~h}$ at $80^{\circ} \mathrm{C}$ in a Somos dryer prior to processing. Since EVOH is sensitive to thermal degradation and difficult to extrude, it was coextruded with LDPE with no tie layer for easy delamination of the different layers. $\mathrm{PE} / \mathrm{EVOH} / \mathrm{PE}(35 / 30 / 35 \mathrm{wt} \%)$ films were prepared by coextrusion using two single-screw extruders of $20 \mathrm{~mm}$ diameter and length to diameter ratio of 20 (L/D: 20:1) from Scamex (France), combined in a classical $\mathrm{A} / \mathrm{B} / \mathrm{A}$ feedblock. The temperature profile was set at $220 / 220 / 220 / 220 / 220^{\circ} \mathrm{C}$ and $220^{\circ} \mathrm{C}$ for the barrel and the die, respectively, with a screw speed of $30 \mathrm{rpm}$. The chill-roll temperature was adjusted to $40^{\circ} \mathrm{C}$, and the final thickness of the EVOH44 film was around $300 \mu \mathrm{m}$.

\subsection{Characterization methods}

\subsubsection{Thermogravimetric analysis (TGA)}

TGA was carried out on a Q500 apparatus from TA Instruments (USA) under an oxygen or nitrogen flow of $60 \mathrm{ml} / \mathrm{min}$. A first heating ramp from room temperature to $200^{\circ} \mathrm{C}$ at $10^{\circ} \mathrm{C} / \mathrm{min}$ followed by a subsequent isothermal step of $10 \mathrm{~min}$ have been performed. The samples were then cooled to $155^{\circ} \mathrm{C}$ and held at that temperature for $240 \mathrm{~min}$. Finally, the sample was cooled down to $50^{\circ} \mathrm{C}$ and heated up to $200^{\circ} \mathrm{C}$ at $10^{\circ} \mathrm{C} / \mathrm{min}$.

\subsubsection{Differential scanning calorimetry (DSC)}

DSC was performed using a Q1000 apparatus from TA Instruments (USA), calibrated with an indium standard scanned at $10^{\circ} \mathrm{C} / \mathrm{min}$. Samples were cut from the extruded EVOH44 films, and their weights ranged typically from 2 to $8 \mathrm{mg}$. For non-isothermal and isothermal crystallization, all the samples were 
first heated to $200^{\circ} \mathrm{C}$ and held at this temperature for 10 min to erase their thermal history.

For non-isothermal crystallization, samples were then cooled to $20^{\circ} \mathrm{C}$ at different cooling rates $(2,5$, 10 and $50^{\circ} \mathrm{C} / \mathrm{min}$ ) and heated again to $200^{\circ} \mathrm{C}$ at $10^{\circ} \mathrm{C} / \mathrm{min}$. For isothermal crystallization, they were cooled at $50^{\circ} \mathrm{C} / \mathrm{min}$ to $138,142,147,150$, and $155^{\circ} \mathrm{C}$, then maintained at these temperatures for various times of $15,15,30,60$, and 240 min respectively. For isothermal crystallization at $142^{\circ} \mathrm{C}$, additional times were investigated $(2,5,10,20,60$, and $240 \mathrm{~min})$. After completion of the crystallization process, the samples were heated at $10^{\circ} \mathrm{C} / \mathrm{min}$ to $200^{\circ} \mathrm{C}$, both directly after crystallization and after an intermediate cooling step at $5{ }^{\circ} \mathrm{C} / \mathrm{min}$ to $20^{\circ} \mathrm{C}$.

\subsubsection{Polarized optical microscopy (POM)}

$15 \mu \mathrm{m}$ thin slices of EVOH44 were cut from the cross-section of the film using an LKB microtome equipped with a glass knife. The samples were put between two glass substrates, set in a Linkam THMS600 hot stage (Waterfield, UK) connected to a liquid nitrogen cooling pump. The heating stage was put under an Axio imager 2 microscope from Zeiss (Germany), and images in transmission mode were recorded with a camera (AxioCam CCD-2Mc) each 1 second. Isothermal crystallization was performed by heating sample to $200^{\circ} \mathrm{C}$ at high speed $\left(150^{\circ} \mathrm{C} / \mathrm{min}\right)$, holding the temperature at this value for $10 \mathrm{~min}$ to erase the thermal history, then cooling at $150^{\circ} \mathrm{C} / \mathrm{min}$ to 155 or $145^{\circ} \mathrm{C}$, and held at these temperatures for 60 and $30 \mathrm{~min}$, respectively.

\subsubsection{Atomic force microscopy (AFM)}

Multimode atomic force microscopy (AFM) equipped with Nanoscope V controller from Veeco (USA) was used in the tapping mode. The tips with a spring force of $40 \mathrm{~N} / \mathrm{m}$ and an oscillation frequency of $300 \mathrm{kHz}$, were obtained from BudgetSensors. The EVOH44 film was placed on a mica substrate, introduced in a heating stage, heated to $200^{\circ} \mathrm{C}$ for $10 \mathrm{~min}$, and then cooled to 150 or $145^{\circ} \mathrm{C}$ with no precise control of the rate of the cooling ramp.

\subsubsection{Small angle light scattering (SALS)}

$100 \mu \mathrm{m}$ thick extruded films were sandwiched between microscope glasses and crystallized isothermally in Linkam THMS600 hot stage (Waterfield, UK) by heating samples at $150^{\circ} \mathrm{C} / \mathrm{min}$ to $200^{\circ} \mathrm{C}$, holding at this temperature for $10 \mathrm{~min}$, then cooling at $150^{\circ} \mathrm{C} / \mathrm{min}$ to $138,145,147$ and $150^{\circ} \mathrm{C}$, and crystallizing at these temperatures for $15,15,30$ and $60 \mathrm{~min}$, respectively. The scattering patterns of the films were recorded under Hv polarization conditions (crossed polarizers) using a He-Ne laser with a wavelength $(\lambda)$ of $632.8 \mathrm{~nm}$.

\subsubsection{Wide angle $X$-ray scattering (WAXS)}

WAXS measurements were performed on the SWING beam line of the Soleil Synchrotron facility (St. Aubin, France), with a monochromator set at $17 \mathrm{keV}$ [30]. Using a CCD detector at $0.553 \mathrm{~m}$ from the sample, diffraction patterns were recorded for reciprocal spacing $q=4 \pi \sin \theta / \lambda$ (where $2 \theta$ is the scattering angle and $\lambda=0.077 \mathrm{~nm}$ is the X-ray wavelength) varying between $0.0019-0.61 \mathrm{~nm}^{-1}$ with an exposure time of $5 \mathrm{~s}$. Foxtrot software was used to obtain 1D WAXS curves by circular averaging of the full $2 \mathrm{D}$ images $\left(0-360^{\circ}\right)$. Isothermal crystallization was carried out in Linkam (UK) THMS600 hot stage according to the same protocol as used for the films prepared for SALS analysis. Diffractograms were treated with Fityk software for deconvolution of the crystalline and amorphous phases and the different crystalline peaks.

\subsubsection{Small angle $X$-ray scattering (SAXS)}

SAXS-2D was used for the determination of long periods of lamellar structure and lamellae thickness of EVOH44 samples. $200 \mu \mathrm{m}$ thick extruded films were sandwiched between Kapton foils and mica plates and crystallized isothermally in Linkam THMS600 hot stage, according to the same protocol as used for the films prepared for SALS and WAXS analysis. A $1.2 \mathrm{~m}$ long Kiessig-type SAXS camera was coupled to GeniX Cu-LD Xenocs (France) Xray system $(\mathrm{Cu} \mathrm{K} \alpha$, wavelength $0.154 \mathrm{~nm}$, operating at $50 \mathrm{kV}$ and $1 \mathrm{~mA}$ ). The patterns were recorded with a Pilatus $100 \mathrm{~K}$ solid-state detector from (Dectris, Switzerland).

\section{Results and discussion}

\subsection{Thermal analysis}

TGA was first conducted to verify the thermal stability of the EVOH44 during the different thermal treatments carried out with the different techniques. TGA curves (not shown) show no significant modification of the evolution of the mass during the analyses under nitrogen or oxygen, which seems to indicate a stability of the copolymer under those conditions. Figure 1a 
displays the DSC scans of non-isothermal crystallization for different cooling rates $(2,5,10$, and $50^{\circ} \mathrm{C} / \mathrm{min}$ ). Classically, the crystallization peak shifts towards the lower temperatures (from 146 to $135^{\circ} \mathrm{C}$ ) as the cooling rates increases from 2 to $50^{\circ} \mathrm{C} / \mathrm{min}$. A second very small exothermic peak around $90^{\circ} \mathrm{C}$ is also present, similarly to what was observed by $\mathrm{Su}$ et al. [20]. Preliminary experiments of POM observation of nucleation and growth of the crystals have evidenced a very fast crystallization. This rapid crystallization may be due to preexisting nuclei, and several conditions were tested for the annealing pretreatment to erase them (up to $250^{\circ} \mathrm{C}$ during $10 \mathrm{~min}$ ) with no substantial observed differences.

Since the crystallization of EVOH44 is very fast, the highest cooling rate $\left(5^{\circ} \mathrm{C} / \mathrm{min}\right)$ was chosen to reach the selected temperature of isothermal crystallization in order to avoid the beginning of the crystallization during the cooling. According to Figure 1a, when cooling the sample at $50^{\circ} \mathrm{C} / \mathrm{min}$, the lowest isothermal crystallization temperature is $138^{\circ} \mathrm{C}$.

Figure $1 \mathrm{~b}$ shows the variation of enthalpy as a function of time during isothermal crystallization at different temperatures $(138,142,145,147,150$, and $\left.155^{\circ} \mathrm{C}\right)$. It appears that for the lowest temperatures $\left(138\right.$ and $\left.142^{\circ} \mathrm{C}\right)$, i.e., for the highest undercooling $\Delta T$, the exotherm peak is truncated, suggesting that crystallization begins during cooling before reaching the target temperature. When the temperature increases, crystallization slows down significantly, leading to a very broad exothermic crystallization peak hardly distinguishable from the baseline. This indicates that the temperature range for isothermal crystallization is very narrow.

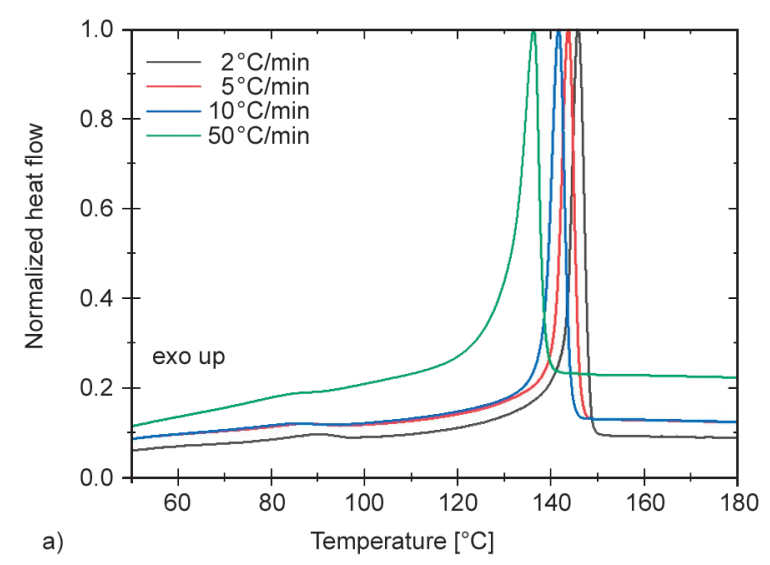

The melting endotherms of the samples after isothermal crystallization at different temperatures scanned at $10^{\circ} \mathrm{C} / \mathrm{min}$, are shown in Figure 2a (both with and without subsequent cooling after isothermal crystallization). The melting curves reveal the presence of several peaks (two or three), designated by $T_{\mathrm{m} 1}, T_{\mathrm{m} 2}$ and $T_{\mathrm{m} 3}$, respectively, from the lowest to the highest temperatures. Such multiple melting peaks are not observed after continuous cooling from the melt, i.e., for non-isothermal crystallization (dynamic crystallization), whatever the cooling rate. Figure $2 b$ presents the evolution of the multiple peaks as a function of the isothermal crystallization temperature, and values of the melting enthalpy associated with the peaks are given in Table 1.

Similar multiple melting peaks have been widely observed for both homopolymers (PEEK, PET, PLA, iPP, PBS, iPS ...) [31-38] and copolymers [35, 3942]. It generally appears difficult to ascertain the cause of this phenomenon that largely depends on the polymer and crystallization conditions. It can be attributed to several different factors: melting, recrystallization, and remelting during heating, molar mass segregation during crystallization, formation of several crystalline populations with different morphologies (such as lamellar thickness, perfection, or stability) or crystal structures (polymorphism). In our case, the lowest melting temperature peak $\left(T_{\mathrm{m} 1}\right)$ always appears slightly above the crystallization temperature. When the crystallization temperature is low, i.e., below $145^{\circ} \mathrm{C}$, the $T_{\mathrm{m} 1}$ peak does not exist or is barely discernable. As the crystallization temperature increases, this peak becomes more pronounced. In our case, the peak can be assigned to the

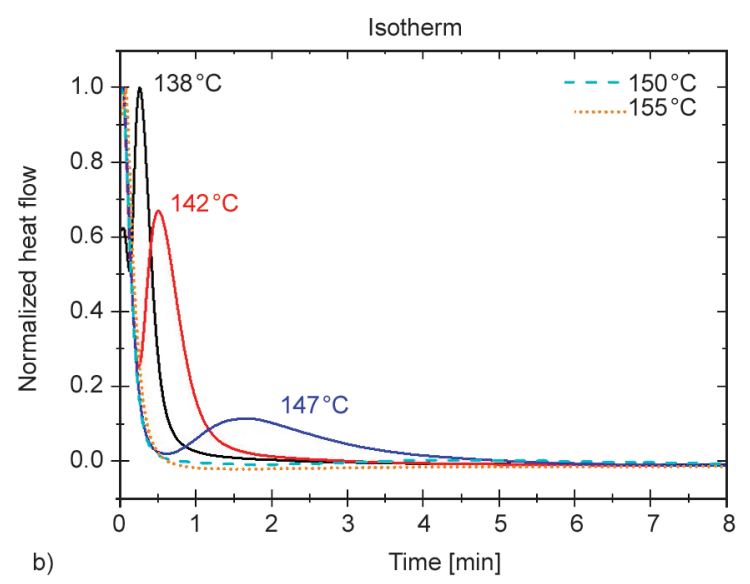

Figure 1. DSC thermograms of EVOH44 a) non-isothermal crystallization at different cooling rates $\left(2,5,10\right.$ and $\left.50^{\circ} \mathrm{C} / \mathrm{min}\right)$, b) isothermal crystallization at different temperatures $\left(138,142,147,150,155^{\circ} \mathrm{C}\right)$ after cooling from $200^{\circ} \mathrm{C}$ at $50^{\circ} \mathrm{C} / \mathrm{min}$. 

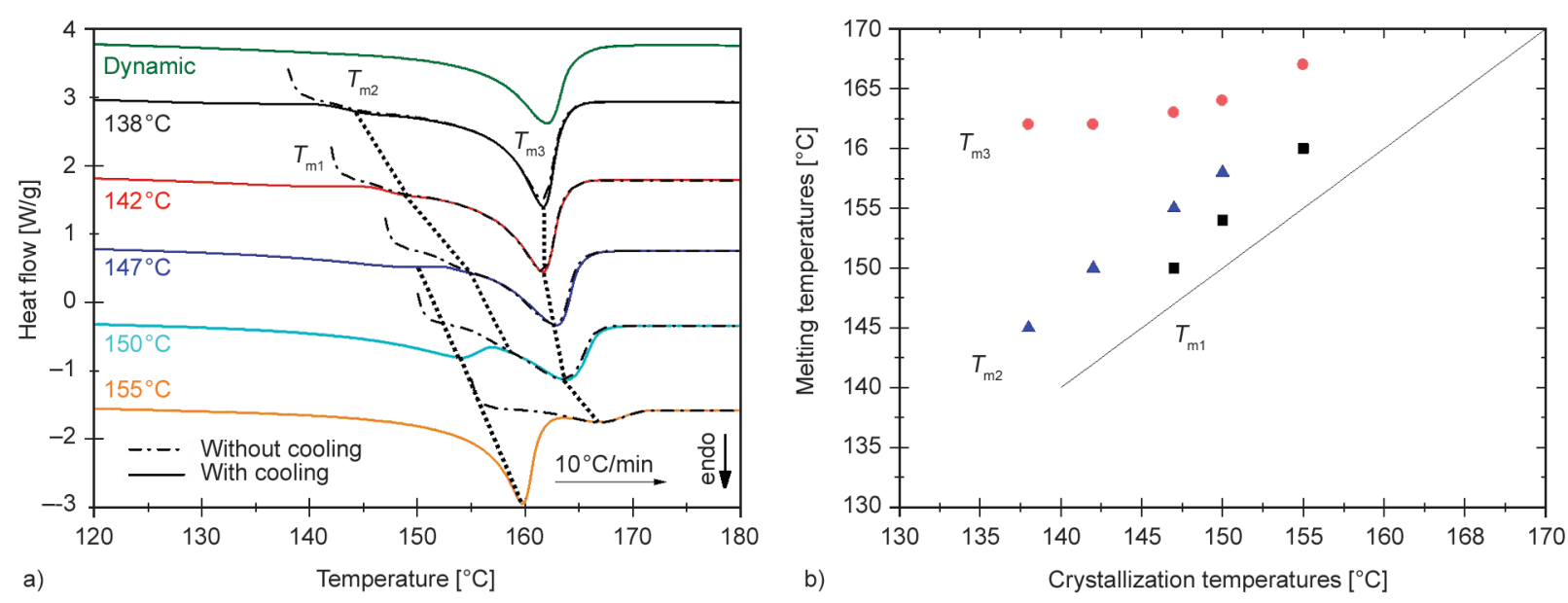

Figure 2. DSC thermograms showing the melting peaks of isothermally crystallized samples (heating rate of $10^{\circ} \mathrm{C} / \mathrm{min}$, endo - down), both directly after crystallization (dashed line) and after an intermediate cooling step at $5^{\circ} \mathrm{C} / \mathrm{min}$ to $20^{\circ} \mathrm{C}$ (full line) a); evolution of the melting peak temperatures as a function of crystallization temperature b).

Table 1. Values of melting peak temperatures of the different peaks and values of the associated total melting enthalpy, as well as $T_{\mathrm{m} 1}$ and $T_{\mathrm{m} 3}$ enthalpy.

\begin{tabular}{|c|c|c|c|c|c|c|}
\hline $\begin{array}{c}\boldsymbol{T}_{\mathbf{c}} \\
{\left[{ }^{\circ} \mathbf{C}\right]}\end{array}$ & $\begin{array}{c}\boldsymbol{T}_{\mathrm{m} 1} \\
{\left[{ }^{\circ} \mathbf{C}\right]}\end{array}$ & $\begin{array}{c}\boldsymbol{T}_{\mathbf{m} 2} \\
{\left[{ }^{\circ} \mathbf{C}\right]}\end{array}$ & $\begin{array}{c}\boldsymbol{T}_{\mathbf{m} 3} \\
{\left[{ }^{\circ} \mathbf{C}\right]}\end{array}$ & $\begin{array}{c}\mathbf{T o t a l}_{\boldsymbol{\Delta}} \boldsymbol{\Delta} \boldsymbol{H}_{\mathbf{m}} \\
{[\mathbf{J} / \mathbf{g}]}\end{array}$ & $\begin{array}{c}\Delta \boldsymbol{H}\left(\boldsymbol{T}_{\mathrm{m} 1}\right) \\
{[\mathbf{J} / \mathbf{g}]}\end{array}$ & $\begin{array}{c}\Delta \boldsymbol{H}\left(\boldsymbol{T}_{\mathrm{m} 3}\right) \\
{[\mathbf{J} / \mathbf{g}]}\end{array}$ \\
\hline 138 & - & 145.38 & 161.7 & $65.4 \pm 1.0$ & 2.9 & 68.8 \\
\hline 142 & 141.5 & 149.3 & 162.3 & $71.2 \pm 2.3$ & 6.0 & 65.3 \\
\hline 147 & 149.5 & 154.9 & 162.9 & 65.3 & 17.4 & 53.2 \\
\hline 150 & 152.2 & 157.9 & 164.8 & $62.9 \pm 4.4$ & 27.5 & 45.7 \\
\hline 155 & 159.5 & - & 167.4 & 62.4 & 59.4 & 7.4 \\
\hline
\end{tabular}

EVOH44 fraction that did not crystallize isothermally but during subsequent cooling. This is confirmed by the fact that when the samples were heated directly after isothermal crystallization, the first melting peak disappeared (dotted curves). It points out the fact that when crystallization temperature is higher than $145^{\circ} \mathrm{C}$, a complete crystallization is not achieved and requires a higher supercooling, which will be discussed later.

As shown in Figure 2a, a small shoulder $\left(T_{\mathrm{m} 2}\right)$ is observed in the upper melting peak temperature $\left(T_{\mathrm{m} 3}\right)$ for the isothermal crystallized samples. Such a shoulder has already been observed by some authors for annealed EVOH [43, 44] and has been attributed to the formation of non-perfect lower melting crystallites or associated with the melting of crystallites with different lamella thicknesses. This small shoulder appears systematically around $10^{\circ} \mathrm{C}$ above the crystallization temperature and could correspond to the socalled annealing peak, whose origin is widely discussed in the literature [37]. Additional isothermal crystallization performed at $142{ }^{\circ} \mathrm{C}$ for various times (from 1 to $240 \mathrm{~min}$ ) show that this peak does not appear from the beginning of the crystallization but after a longer crystallization time of $5 \mathrm{~min}$ (Figure 3). Another noteworthy point is the slight shift to higher temperatures of the upper-temperature peak $\left(T_{\mathrm{m} 3}\right)$ that could be the signature of a classical lamella thickening during the isothermal crystallization.

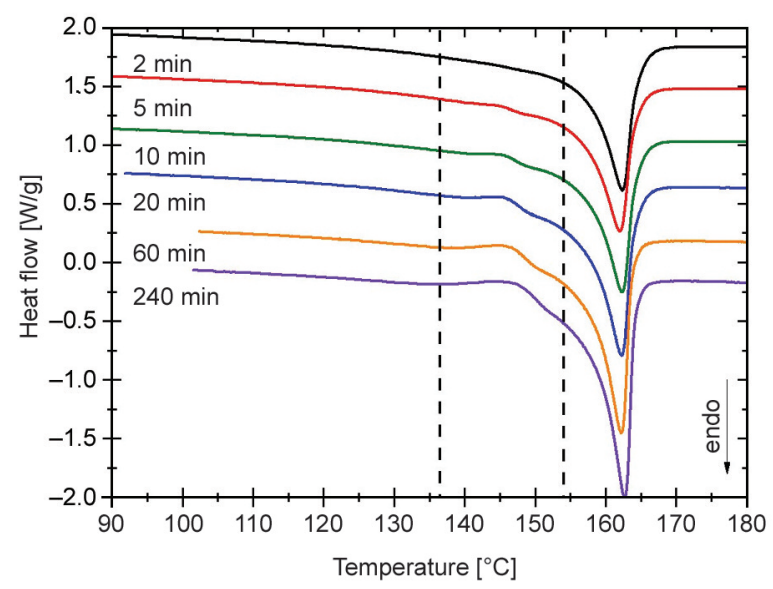

Figure 3. Heating scan (at $10^{\circ} \mathrm{C} / \mathrm{min}$ ) applied to EVOH44 after crystallization at $142{ }^{\circ} \mathrm{C}$ for different times and subsequently cooled to $20^{\circ} \mathrm{C}$ at $50^{\circ} \mathrm{C} / \mathrm{min}$. 


\subsection{WAXS results}

Wide angle X-ray scattering (WAXS) experiments were performed to gain information about the structure of EVOH44 and its evolution during isothermal crystallization. The diffractogram of an extruded film (see Figure 4) exhibits orthorhombic lattice typically observed for this copolymer composition by

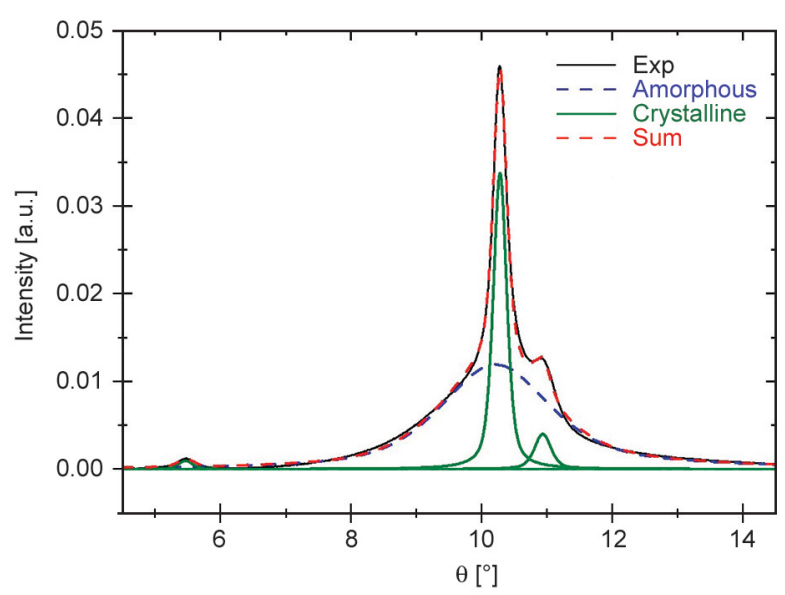

Figure 4. EVOH44 WAXS diffractogram, including the deconvolution of the crystalline and the amorphous part. previous authors $[7,15,45]$, with mainly three characteristic peaks corresponding to the following crystallographic planes: (110) and (200) from the orthorhombic PE lattice and (100) from the PVOH monoclinic lattice.

Isothermal experiments between 138 to $150^{\circ} \mathrm{C}$ were followed by WAXS using a synchrotron radiation source. The short exposure time $(5 \mathrm{~s})$ and the quick rate of the heating stage $\left(150^{\circ} \mathrm{C} / \mathrm{min}\right)$ allowed following the isothermal crystallization from the beginning. Figure 5a shows the typical WAXS patterns as a function of time during isothermal crystallization of EVOH44 at $142^{\circ} \mathrm{C}$. While the beginning of the annealing highlights no diffraction peak, indicating that the sample was amorphous, diffraction peaks appear after several tens of seconds and start to grow simultaneously with time, suggesting a mixed crystalline form. Those peaks correspond exactly to the ones obtained after non-isothermal crystallization. Still, a slight shift towards higher angles was observable for all three peaks (Figures $5 \mathrm{~b}$ and $5 \mathrm{c}$ ) during crystallization, though more pronounced for the (200)

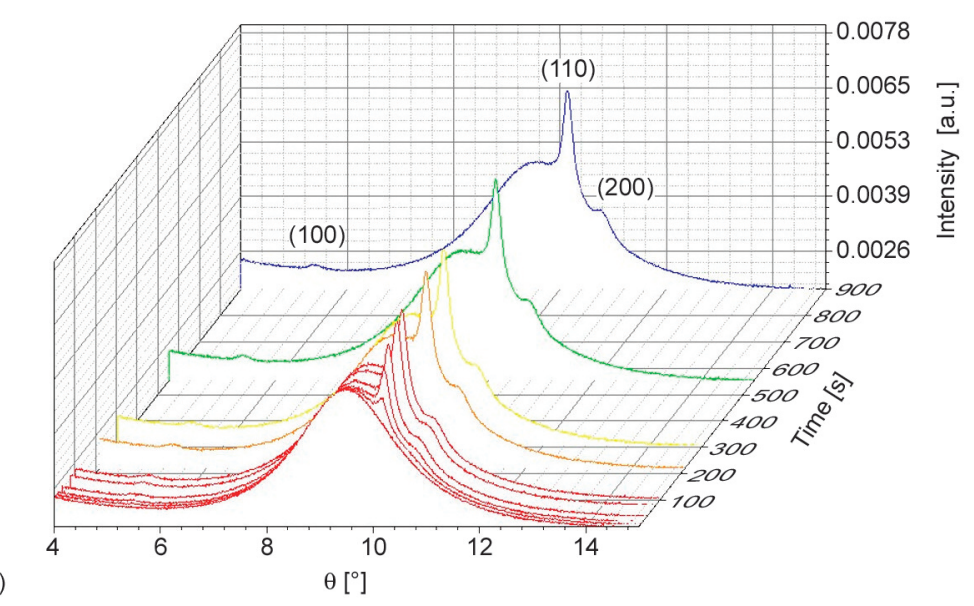

a)

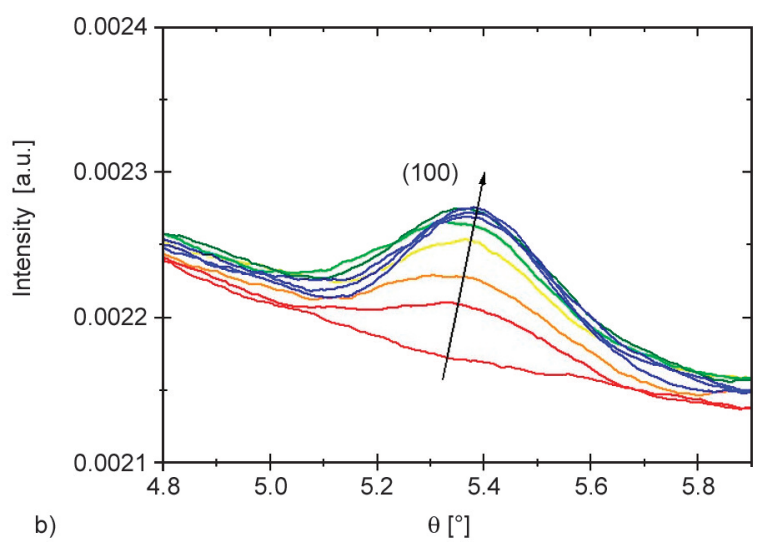

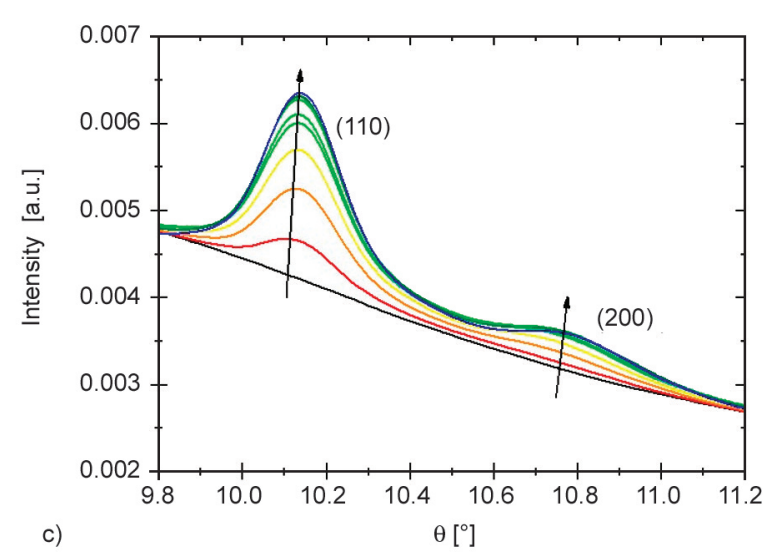

c)

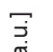 $\stackrel{\mathbb{0}}{7}$


peak. This shift is the signature of a slight contraction of the lattice, already observed previously by some authors when cooling the samples at slower rates [15] or thermally annealing the samples at higher temperatures [46]. It was interpreted as an improvement of crystalline morphology. In the case of EVOH32, a clear transition was observed from a defective orthorhombic morphology to a more thermodynamically stable monoclinic unit cell, with a slow cooling rate or throughout annealing at high temperature. This transition was reflected first, by a broadening of the (110) peak and a shift to higher angles of the (200) peak, and then by a splitting of the (110) peak into the two monoclinic (101) and (10̄) peaks [15].

Still, in those previous studies, no such clear transition was observed for EVOH44, for which the orthorhombic unit cell was maintained regardless of the cooling rate and the crystallization temperatures. Moreover, by measuring lattice parameters ' $a$ ' and ' $b$ ' as a function of time during isotherm, no significant variation has been evidenced (see Figure 6). Since EVOH44 is located, with a composition of $56 \mathrm{~mol} \%$ of vinyl alcohol, very close to the orthorhombicmonoclinic transition [7], it is possible that we observe, during this isothermal crystallization, the beginning of the transition towards the more stable monoclinic lattice.

By comparing the diffraction patterns at the end of isothermal experiment for the different crystallization temperatures, as shown in Figure 7a, it appears clearly that the crystallization is not completely finished at the highest temperatures. This would suggest a significant slowing-down of the crystallization or rather a partial crystallization at high temperatures, which will be addressed later. Moreover, during the cooling step or the isothermal crystallization, the evolution

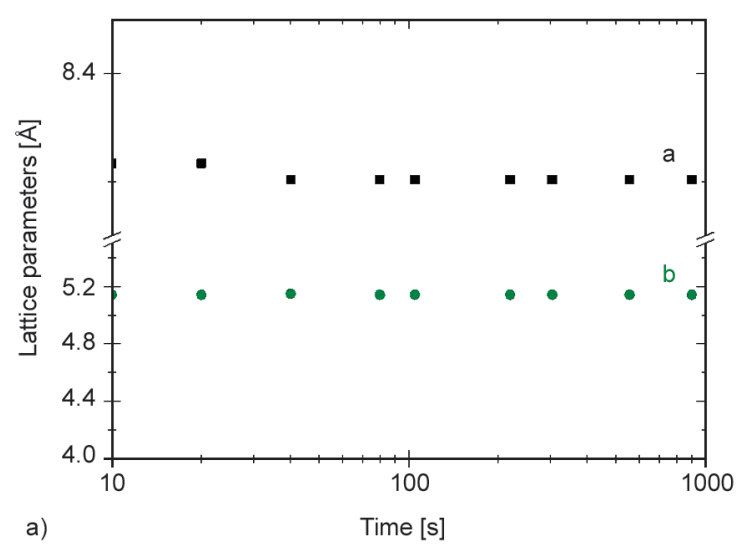

of the (100) peak of monoclinic lattice (Figure 7b) follows the same shift as the (110) and (200) peaks (Figure 7c). This observation suggests that $\mathrm{VOH}$ units and ethylene units are involved in the same crystalline structure regardless of the thermal treatment.

\subsection{Morphological analysis}

To provide support for the previous conclusions, several complementary morphological analyses have been conducted using different techniques.

\subsubsection{Polarized optical microscopy (POM)}

Polarized optical microscopy (POM) was first used to follow the isothermal crystallization at 155 and $145^{\circ} \mathrm{C}$. In both cases, the nucleation process and the growth of the supermolecular structure could not be observed. Figure 8 displays the images obtained using POM after isothermal crystallization at both temperatures and after cooling to $20^{\circ} \mathrm{C}$. In both cases, the formed crystalline structures are very small (one can distinguish those with sizes from around 1 to a few micrometers), revealing an approximately spherical symmetry and exhibiting a rather uniform Maltese Cross, suggesting a crystallization with the formation of spherulitic and lamellar morphologies. It is to notice that no substantial differences are observed between the structures obtained at different crystallization temperatures, neither in the spherulite type nor in their dimension.

\subsubsection{Small-angle light scattering (SALS)}

The observations performed with an optical microscope were complemented by SALS (Figure 9). The four-leaf patterns obtained for all the films are typical of a spherulitic structure. The intensity profiles at $\mu=$ $45^{\circ}$ azimuthal direction are shown in Figure 10. For

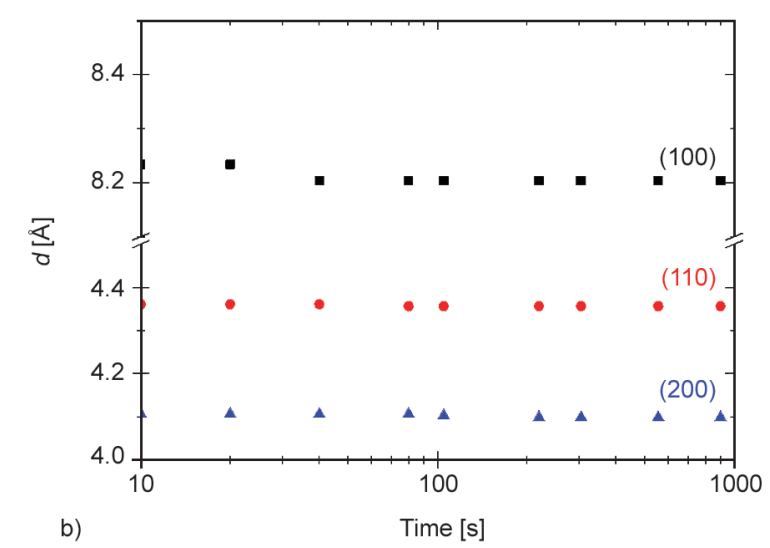

Figure 6. Evolution of the lattice parameters (a) and the spacing lattice (b) as a function of time during isothermal crystallization of EVOH44 at $142^{\circ} \mathrm{C}$. 

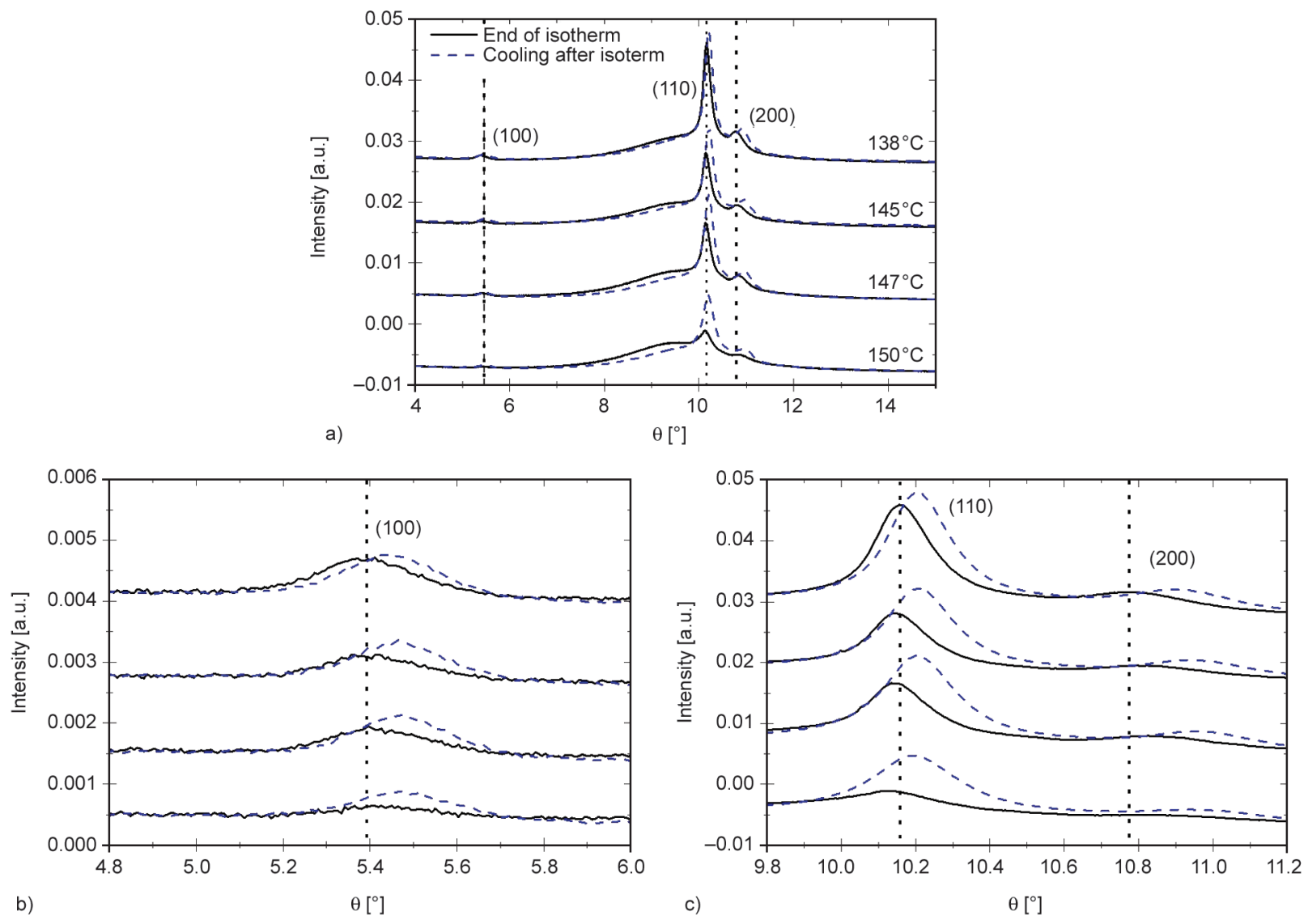

Figure 7. EVOH44 diffraction patterns at the end of the isothermal experiments (solid lines) and after the subsequent cooling (dashed lines) for different crystallization temperatures a), focus on the characteristic peak corresponding to the (100) plane of PVOH b), focus on the characteristic peaks corresponding to the (110) and (200) planes of PE c).

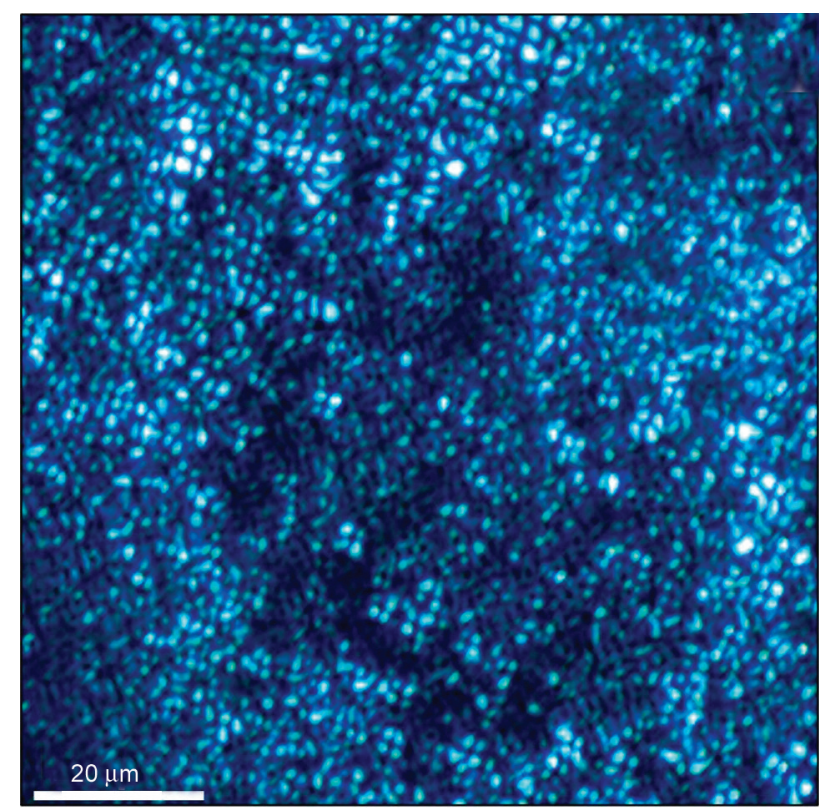

a)

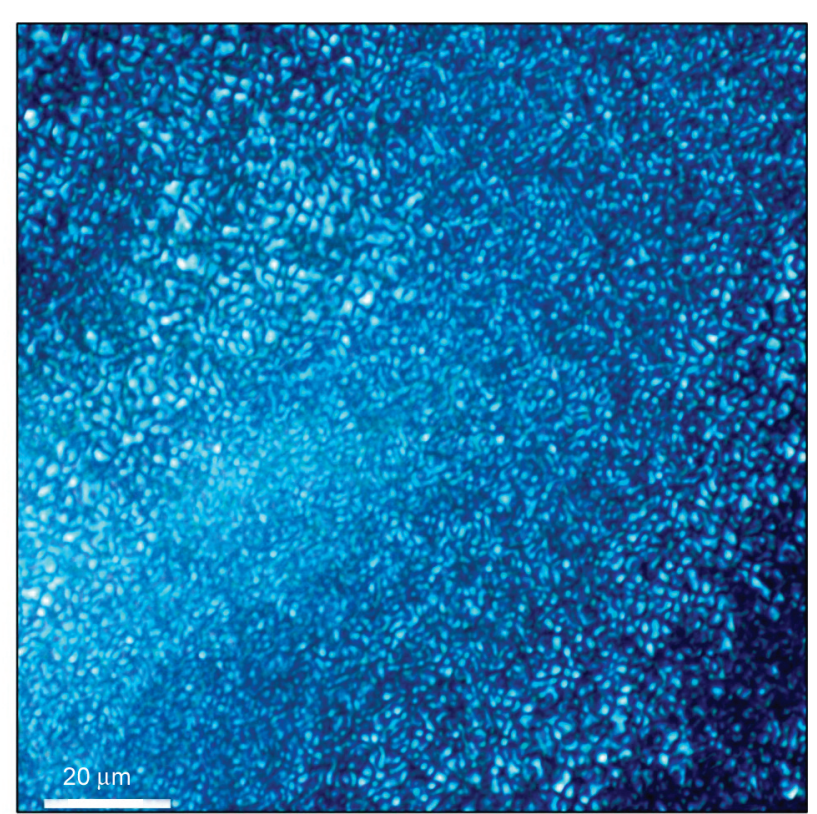

b)

Figure 8. Optical microscopy images of EVOH44 superstructure at room temperature, a) after crystallization for 30 min at $145^{\circ} \mathrm{C}$ and b) for $60 \mathrm{~min}$ at $155^{\circ} \mathrm{C}$.

each profile, the angle at a maximum of the intensity, $\theta_{\max }$, was determined, and average radii of spherulites, $r_{\mathrm{av}}$, were calculated using Equation (1) [47]:

$$
r_{\mathrm{av}}=\frac{4.09 \lambda}{4 \pi \cdot \sin \frac{\theta_{\max }}{2}}
$$



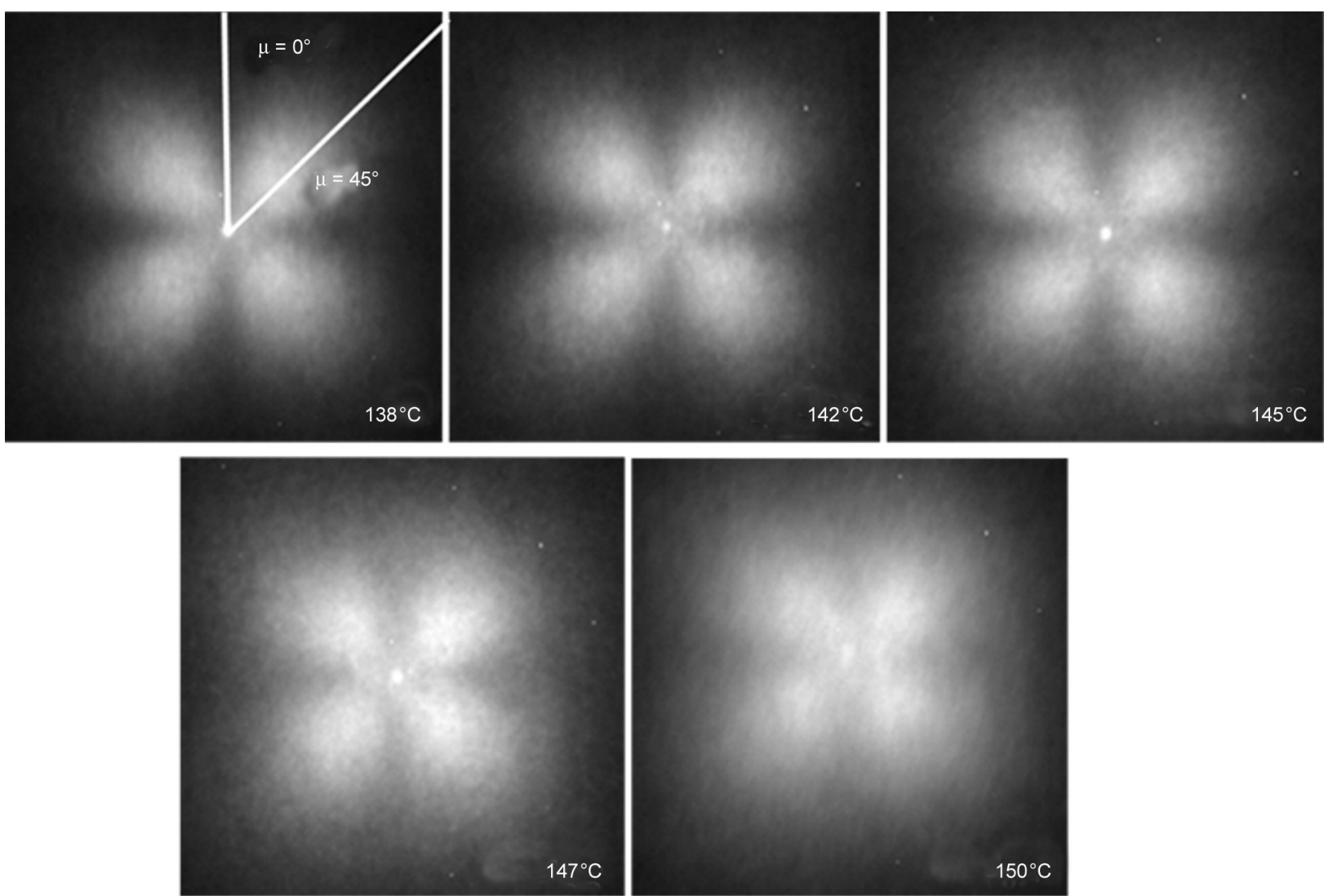

Figure 9. SALS patterns of EVOH44 films crystallized isothermally at various temperatures.

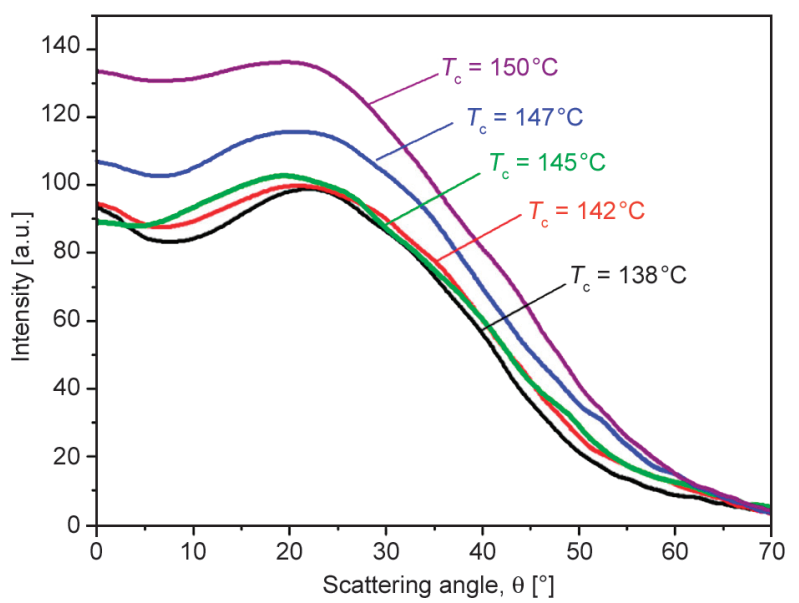

Figure 10. Intensity profiles vs. scattering angle $\theta$ determined from SALS patterns at the azimuthal direction of $45^{\circ}$ for isothermally crystallized EVOH44 films at different temperatures.

Table 2. Average radii of spherulites in EVOH44 films crystallized isothermally at various temperatures.

\begin{tabular}{|c|c|}
\hline $\begin{array}{c}\text { Crystallization temperature } \\
{\left[{ }^{\circ} \mathbf{C}\right]}\end{array}$ & $\begin{array}{c}\boldsymbol{r}_{\text {av }} \\
{[\boldsymbol{\mu} \mathbf{m}]}\end{array}$ \\
\hline 138 & 1.05 \\
\hline 142 & 1.08 \\
\hline 145 & 1.13 \\
\hline 147 & 1.14 \\
\hline 150 & 1.18 \\
\hline
\end{tabular}

The values of $r_{\mathrm{av}}$ are collected in Table 2, revealing spherulites with about $1 \mu \mathrm{m}$ radii and evidencing no significant influence of the crystallization temperature on the dimensions of the spherulites, which is globally consistent with previous observations using POM. It is worth noticing that $r_{\mathrm{av}}$ calculated according to Equation (1) is, in fact, the fifth-order average for 3D-spherulites [48]. Moreover, the scattering intensity at $\mu=0^{\circ}$ (azimuthal direction) was strong, especially at 147 and $150^{\circ} \mathrm{C}$, which indicates strong isotropic scattering and evidences the presence of a less ordered crystalline phase.

\subsubsection{Atomic force microscopy (AFM)}

Because of the very small dimensions of the spherulites, techniques with higher resolution (like SEM or AFM) could be more relevant to identify the crystalline morphology and lamellar structure of EVOH44. At first, SEM was tried using a permanganate etching. Despite different etching times and etchant concentrations, the etched surface was full of holes and no crystalline morphology was observed. Observations using atomic force microscopy (AFM) offered better results to follow EVOH44 crystallization. First, we probed at room temperature the surface of samples previously crystallized at different 


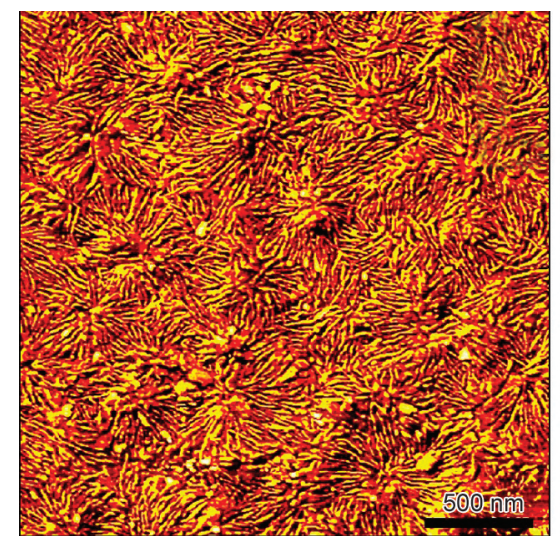

a)

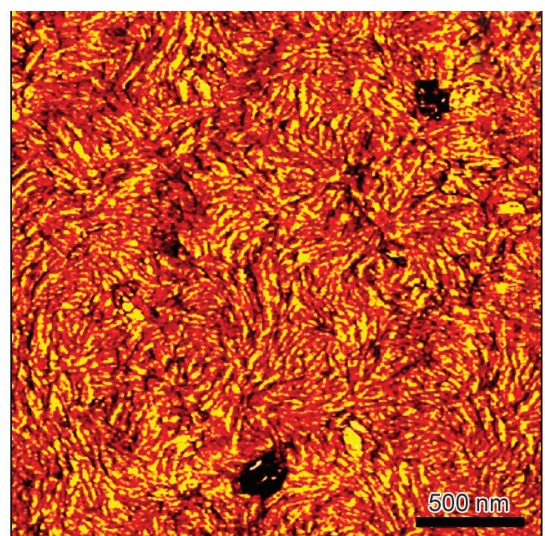

b)

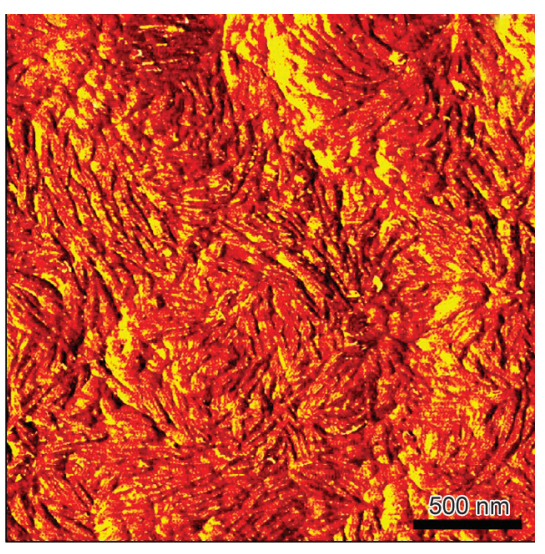

c)

Figure 11. AFM phase images of the free surface of EVOH44 samples cooled to room temperature after crystallization for 2 hours at a) $145^{\circ} \mathrm{C}$, b) $147^{\circ} \mathrm{C}$ and c) $150^{\circ} \mathrm{C}$. The scale bar corresponds to $500 \mathrm{~nm}$.

temperatures for $2 \mathrm{~h}$ and then slowly cooled to room temperature. The images of Figure 11 display spherulite-like structures composed of stacked radial lamellae. Although it seems that the lamellae grew from nucleation centers, the contours and limits of the spherulites do not appear clearly, and some randomly arranged lamellae are also visible.

Secondly, we observed in-situ the crystallization and the formation of spherulites during the isothermal crystallization. We show in Figure 12 several series

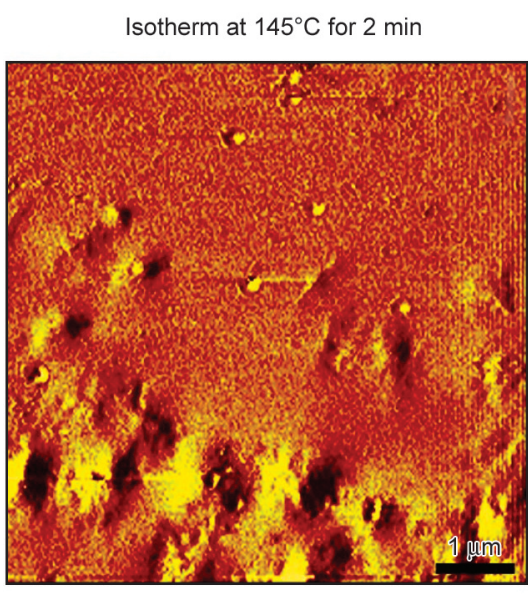

a)

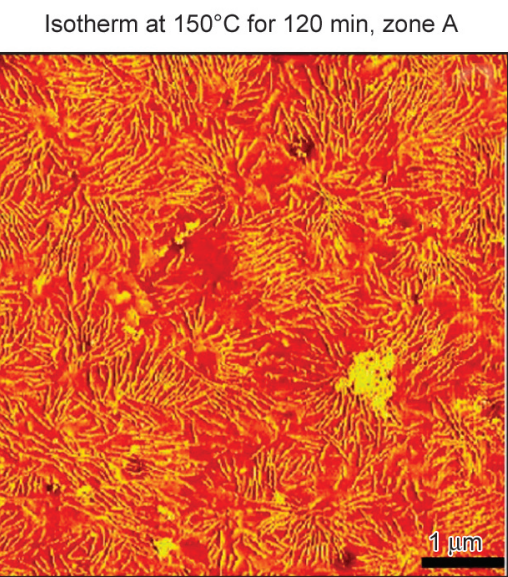

d)
Isotherm at $145^{\circ} \mathrm{C}$ for $5 \mathrm{~min}$

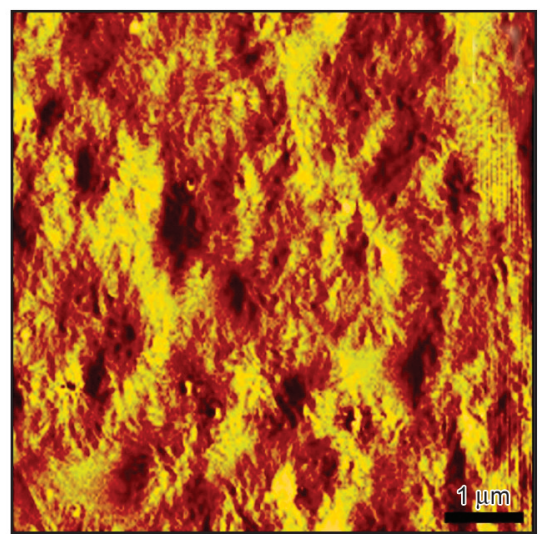

b)

Isotherm at $150^{\circ} \mathrm{C}$ for $120 \mathrm{~min}$, zone $\mathrm{B}$

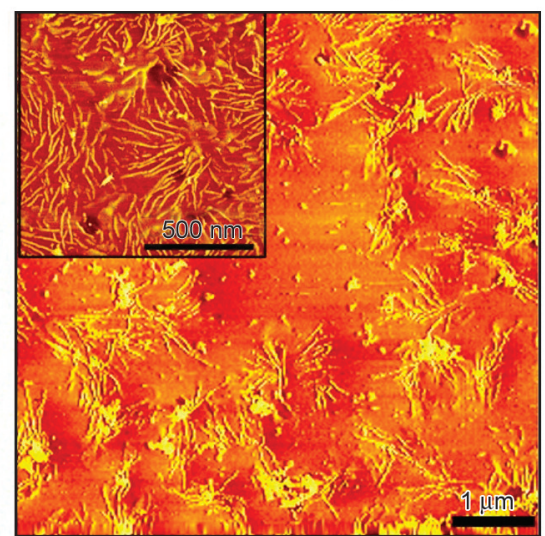

e)
Cooling to $200{ }^{\circ} \mathrm{C}$ after isoterm

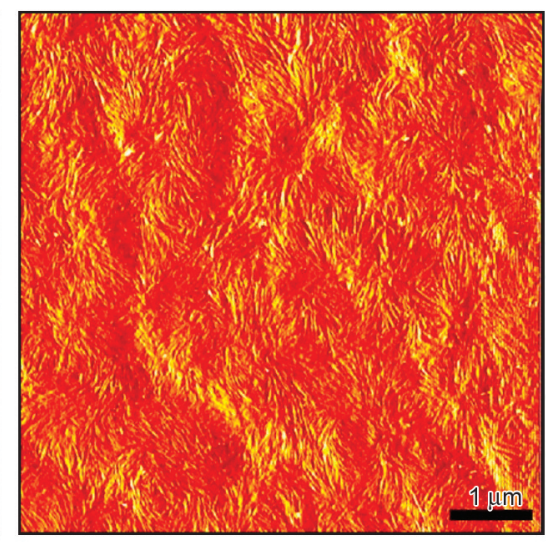

c)

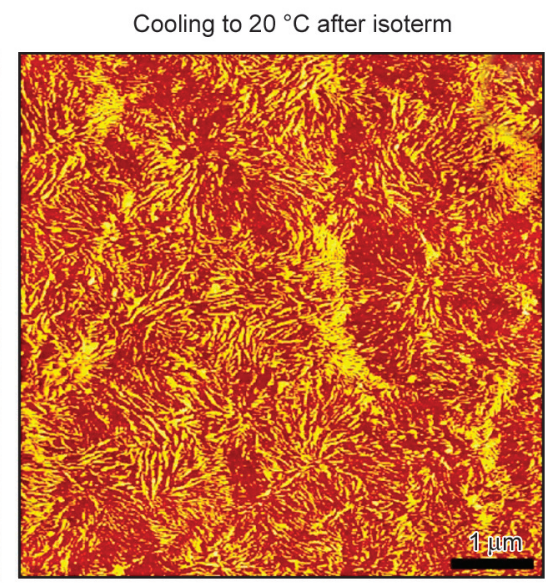

f)

Figure 12. AFM phase image of EVOH44 during annealing at $145^{\circ} \mathrm{C}$ a) and b) and cooling to room temperature c), at $150{ }^{\circ} \mathrm{C}$, two different zones d) and e) and after cooling f). The scale bar corresponds to $1 \mu \mathrm{m}$. 
of AFM images taken at 145 and $150^{\circ} \mathrm{C}$ at various times. At $145^{\circ} \mathrm{C}$, the early stages of crystallization were captured with the melt in the upper part and the beginning of the crystallization in the bottom part of Figure 12a, and after 5 minutes, all the volume was filled with spherulites. The crystallization behavior appeared, however, different at $150^{\circ} \mathrm{C}$ : in some zones (see zone B, Figure 12e), the crystallization was not complete even after $2 \mathrm{~h}$, leaving some areas without any crystals, as if the crystallization was greatly slowed down or even stopped. A closer look at spherulites created during isothermal crystallization (see the inset image in Figure 12e) reveals that the lamellae are grown during the isothermal annealing from a relatively coarse and open structure. The unfilled volume was completely filled after cooling to $20^{\circ} \mathrm{C}$ subsequent to isothermal crystallization (Figure 12f). Unfortunately, the contours of the spherulites are not well defined, and it is impossible to determine whether the lamellae previously formed during isothermal treatment continue to grow and/or to thicken during subsequent cooling, or some others appear in the unfilled space. On this last image, it was impossible to distinguish the lamellae formed during the isothermal crystallization from those formed during the subsequent cooling.

\subsubsection{Small-angle $X$-ray scattering (SAXS)}

SAXS was used to characterize the lamellar structure and investigate the impact of the crystallization temperature on the lamellae thickness. Figure 13a shows the SAXS-2D patterns obtained for EVOH44 samples crystallized isothermally between Kapton foils at different temperatures. Figure $13 \mathrm{~b}$ shows the Kratky plots, $I q^{2} v s . q$, where $I$ is the intensity and $q$ is the
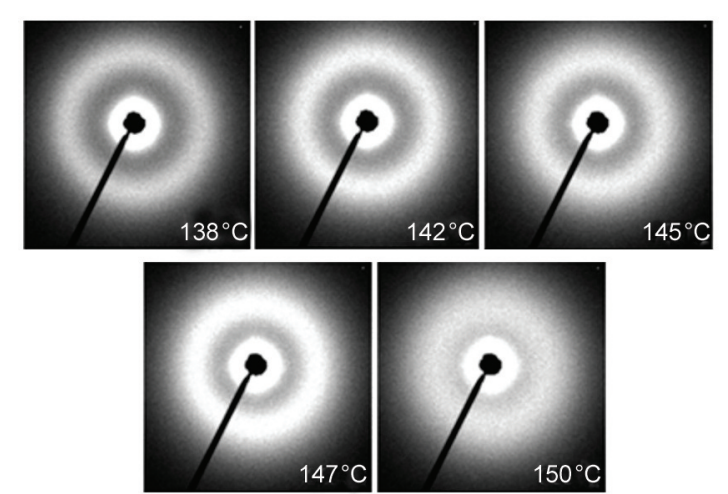

a)
Table 3. Mean long period values $\left(L P_{1}\right)$ calculated using the Bragg equation from the position of the peak maximum of the Kratky plot, mean long period values $\left(L P_{2}\right)$ and mean lamella thickness $\left(L_{\mathrm{c}}\right)$ calculated based on the correlation function for isothermally crystallized EVOH44 films at different temperatures between Kapton foils.

\begin{tabular}{|c|c|c|c|}
\hline $\begin{array}{c}\text { Crystallization } \\
\text { temperature } \\
{\left[{ }^{\circ} \mathbf{C}\right]}\end{array}$ & $\begin{array}{c}\boldsymbol{L P}_{\mathbf{1}} \\
{[\mathbf{n m}]}\end{array}$ & $\begin{array}{c}\boldsymbol{L P}_{\mathbf{2}} \\
{[\mathbf{n m}]}\end{array}$ & $\begin{array}{c}\boldsymbol{L}_{\mathbf{c}} \\
{[\mathbf{n m}]}\end{array}$ \\
\hline 138 & 16.3 & 15.4 & 4.05 \\
\hline 142 & 16.8 & 15.5 & 4.13 \\
\hline 145 & 16.9 & 15.5 & 4.20 \\
\hline 147 & 17.1 & 15.7 & 4.27 \\
\hline 150 & 15.6 & 15.7 & 4.19 \\
\hline
\end{tabular}

scattering vector. The mean long period $(L P)$ values, deduced from the position of the peaks of the Kratky plots, according to the Bragg law, are given in Table 3. In addition, the mean values of lamellae thickness and $L P$ determined based on the correlation function [49] are collected in Table 3. The crystallinity level of isothermally crystallized EVOH44 specimens, 30-35\% as shown further, supports the assignment of $L_{\mathrm{c}}$ to lamellae thickness rather than to amorphous layer thickness. It must also be mentioned that, according to Figure 7, orthorhombic lattice and monoclinic lattice were formed in EVOH44. However, a very small content of the latter was determined by comparing peak areas (around $2 \%$ ), and no evidence of the second long period was found on the Kratky plots.

$L P$ and $L_{\mathrm{c}}$ values shown in Table 3 for films crystallized at different temperatures are similar. They slightly increase with increasing crystallization temperature, indicating, quite classically, slightly thicker lamellae at a higher temperature. However, smaller values are then obtained for the specimen crystallized

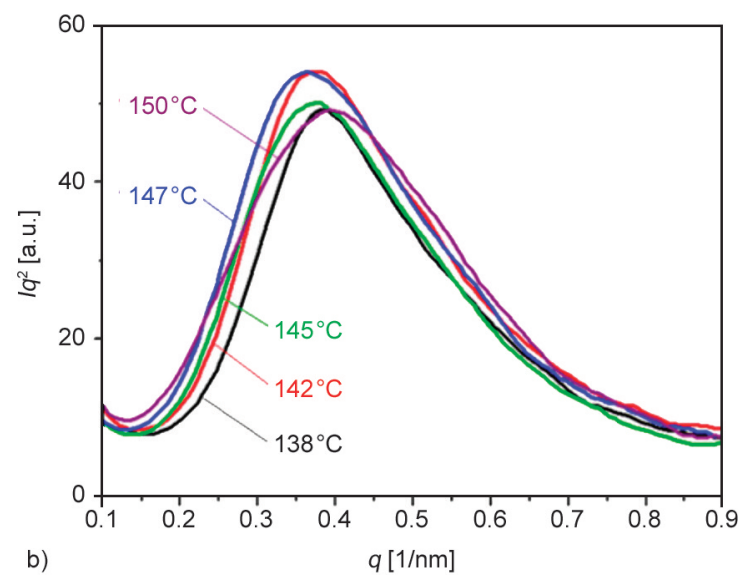

Figure 13. 2D-SAXS patterns a) and Kratky plot $\left(I^{2} v s . q\right)$ b) recorded for isothermally crystallized EVOH44 films at different temperatures. 
at $150{ }^{\circ} \mathrm{C}$. These slightly smaller values could result from incomplete crystallization at this crystallization temperature and crystals formed during subsequent cooling. It is worth mentioning that very similar results were obtained for films crystallized isothermally between mica plates (not shown). However, it must be emphasized that the differences in $L P$ and $L_{\mathrm{c}}$ values are very small, corresponding to a few bonds and indicating the predominant influence of chemical structure rather than crystallization temperature.

\subsection{Crystallization after isothermal step}

The previous observations (DSC and WAXS results, AFM images) have pointed out the fact that EVOH44 cannot always fully crystallize in isothermal conditions, particularly at high temperatures. It was observed as well that further crystallization upon subsequent cooling completed the partial isothermal crystallization. We have tried here to tackle this question, adopting a more quantitative approach by using in-situ WAXS and DSC analysis.

In particular, in-situ WAXS allowed us to follow the crystallization from the beginning and to estimate the degree of crystallinity by separating the amorphous and crystalline contributions (see Figure 4). Plotting the evolution of the degree of crystallinity as a function of time, as shown in Figure 14, is an interesting means to track the progress of crystallization. Obviously, the isothermal crystallization of EVOH44 was characterized by a sharp increase of the degree of crystallinity, followed by stabilization on a plateau value, on which crystallization actually seemed to continue but extremely slowly. The lower

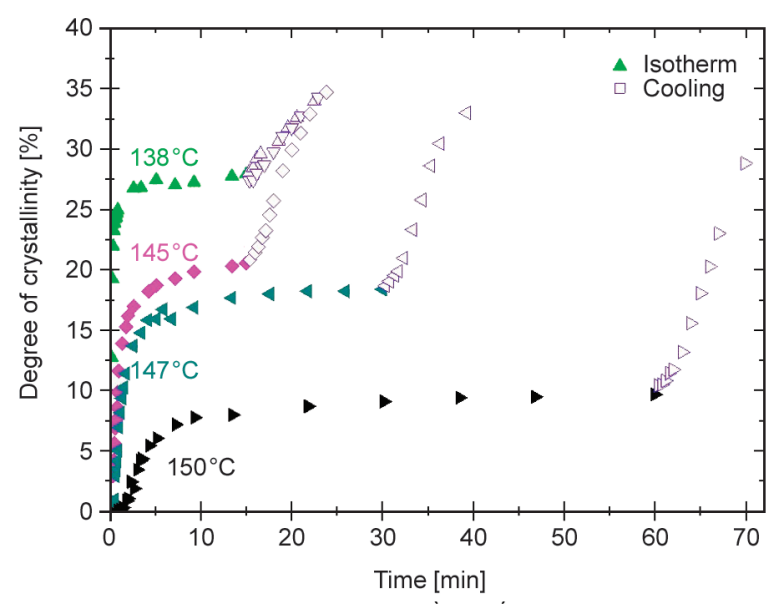

Figure 14. Evolution of EVOH44 degree of crystallinity as a function of time during isotherm (filled symbol) and during subsequent cooling (open symbol) measured by WAXS. the crystallization temperature, i.e., the higher the undercooling, the faster the isothermal crystallization and the higher the degree of crystallinity at which the stabilization occurs. After the isothermal crystallization and stabilization of the crystallization process, only the cooling to ambient temperature allows the continuation of the crystallization. Finally, the degree of crystallinity reached after an isothermal crystallization at $150^{\circ} \mathrm{C}$ and subsequent cooling is slightly lower (around 30\%) than those of samples crystallized at lower temperatures (around 35\%). Similar results and tendencies were obtained with DSC measurements which allowed determining the extent of crystallization in isothermal conditions, depending on time and temperature, and the complementary crystallization upon subsequent cooling (see Figure 15). Moreover, it is worth noticing that the crystallization enthalpy measured for the subsequent crystallization after the isothermal step (i.e., $T_{\mathrm{c} 1}$ ) is in good agreement with the melting enthalpy determined for $T_{\mathrm{m} 1}$ (see Table 1) corresponding to the crystal melting formed during this subsequent cooling.

This behavior is unexpected and deviates from the crystallization process of a regular homopolymer, for which the crystallization should be complete or nearly complete in isothermal conditions below the melting temperature [50]. It is to notice that the upper crystallization temperature $\left(150^{\circ} \mathrm{C}\right)$ is rather high for EVOH44. This temperature is located in the melting endotherm peak observed when heating the polymer after quenching. We expect that at such a temperature, not the entire polymer is capable of crystallizing, and especially the small crystals, e.g., the thinnest lamellae are unstable and are not formed. Still, theoretically, only the equilibrium melting temperature should be of concern in governing the crystallization kinetics. The equilibrium melting temperature of EVOH44 was estimated to be around $175^{\circ} \mathrm{C}$, by Alvarez et al. [51]. Though, the graph of Figure $2 b$ points out the difficulty to determine the equilibrium melting temperature as far as multiple melting peaks appear, as raised by several authors [39, 52, 53], which is often the case for copolymers.

Such multiple-step crystallizations have already been observed previously for different polymer systems: branched polyethylene [54, 55], blends of unbranched and short-chain branched polyethylene [56], copolymers [57, 58], and even for some homopolymers $[32,59]$. For example, Glotin and Mandelkern [54] have noticed that the crystallization of 

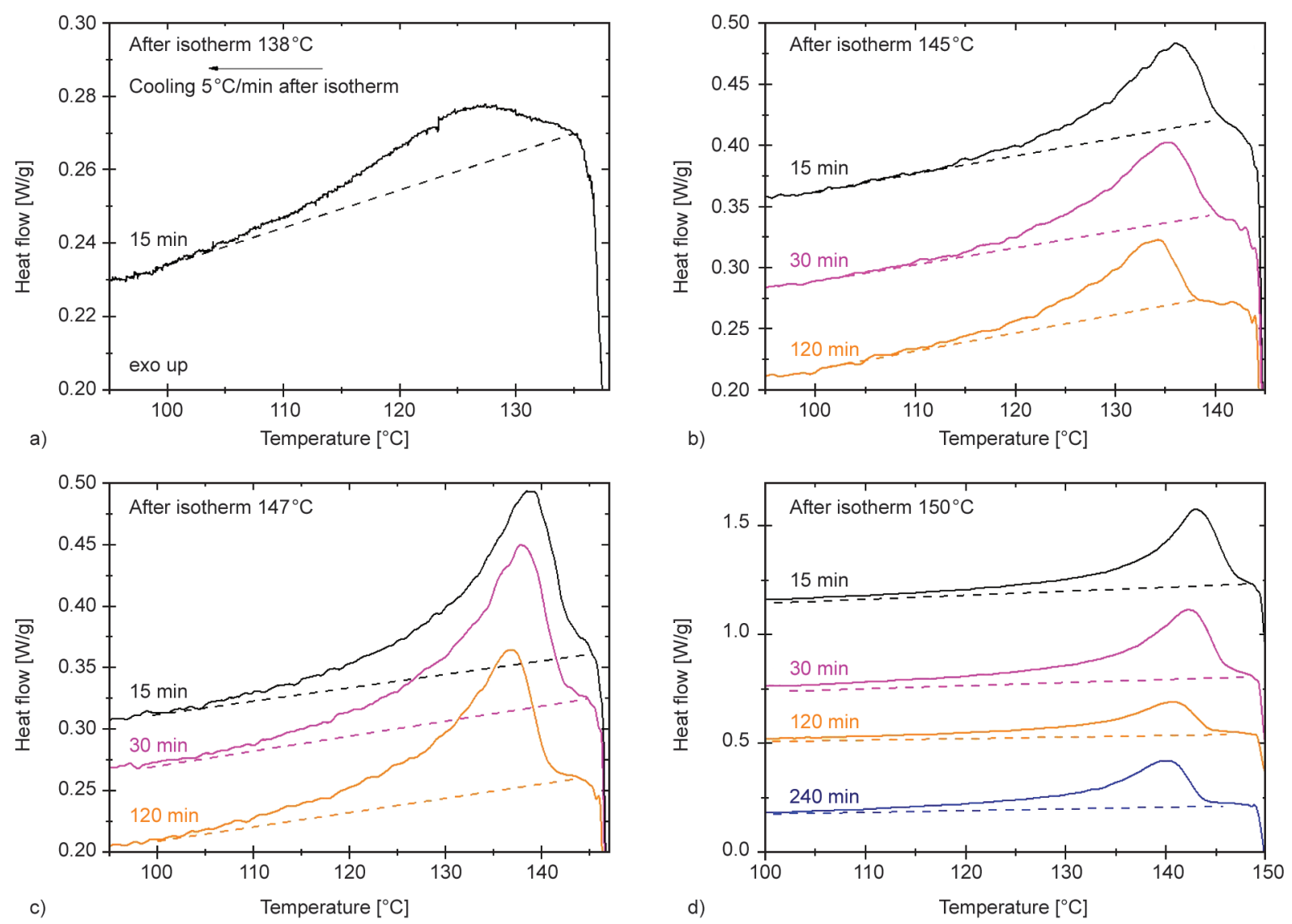

Figure 15. DSC scans of EVOH44 during the subsequent cooling of several isothermal crystallization at a) $\left.138^{\circ} \mathrm{C}, \mathrm{b}\right) 145^{\circ} \mathrm{C}$, c) $147^{\circ} \mathrm{C}$ and d) $150^{\circ} \mathrm{C}$.

branched polyethylene is very sensitive to temperature. Besides, many studies on the crystallization of random copolymers (generally with one non-crystallizable comonomer) have shown that the crystallizable sequence distribution plays an important role in the crystallization process. In this case, the lamellar thickness is not controlled only by the undercooling but also by the sequence of crystallizable units [58]. The sequences that are not long enough to crystallize at a given temperature may crystallize at lower temperatures. A phenomenon of segregation occurs to gather the sequences of the same lengths allowing them to reach the critical dimensions. However, it was observed that usually for those random copolymers, this segregation is hindered by different restrictions (nucleation, overcrowding, pinning) inducing reduced mobility and limited transport of chain segments and leading to incomplete and lower crystallinity [40,60]. Further crystallization requires cooling to lower temperatures and leads generally to less organized structures that have fringed micelle character.

In the case of EVOH44, at medium vinyl-alcohol contents, a strong rejection of short-chain branches has been observed by VanderHart et al. [16] leading to a significant partitioning. The SSA fractionation technique proposed by Franco-Urquiza et al. [17] confirmed the existence in EVOH32 of a strong segregation linked with the presence of the short chain branching that may generate a crystalline distribution during crystallization. The role of the numerous hydrogen bonding and their impact on this segregation are yet to be understood. They could possibly act as an additional physical hindrance to crystallization, as it has been evidenced in PVOH crystallization [61]. This behavior echoes the results of $\mathrm{Su}$ et al. [20], who have pointed out the existence of two regions (temperature range) in the crystallization process of EVOH32 associated to different molecular movements dominated by hydrogen bonds.

\section{Conclusions}

The crystallization habit of EVOH44 has been for the first time investigated combining DSC, X-ray scattering, and other techniques (POM, SALS, AFM). POM observations revealed the presence of very small spherulites, with a mean radius around $1 \mu \mathrm{m}$, but it was impossible to observe the nucleation and the spherulite growth due to a very fast crystallization. 
However, in-situ AFM observations enabled tracking the early crystallization stage and observing the spherulitic morphology, confirmed by SALS analysis, presenting many stacked lamellae of various thicknesses. Isothermal crystallization has evidenced the existence of a two-step crystallization, resembling the process of crystallization in other random copolymers. A first rapid primary step (primary crystallization) corresponds to the spherulite growth that may be inhibited especially at high crystallization temperatures leading to a partial crystallization. Higher undercooling is needed to complete crystallization with a secondary crystallization, generating thinner lamellar structures. Further investigations are needed to explain this behavior and in particular to investigate the role of short chain-ends and hydrogen bonds in this complex crystallization behavior.

\section{Acknowledgements}

This study was achieved within the context of a French FUI project (NOXY II). The authors acknowledge the synchrotron facility SOLEIL - beamline SWING (project $n^{\circ}$ 20171204) and especially J. Perez (beamline manager) and T. Bizien (beamline scientist) for their precious help and advice. The authors would like to thank Dr. S. Tencé-Girault and Dr. S. Roland for fruitfull discussion.

\section{References}

[1] Okaya T., Ikari K.: Ethylene vinyl alcohol copolymers. in 'Polyvinyl alcohol: Developments' (eds.: Finch C. A.) Wiley, Chichester, 196-267 (1992).

[2] Ito K., Li H-L., Saito Y., Yamamoto T., Nishihara Y., Ujihira Y., Nomura K.: Crystallinity dependence of freevolume size and its distribution of ethylene-vinyl alcohol copolymer evaluated by positronium lifetime measurement. Journal of Radioanalytical and Nuclear Chemistry, 257, 191-193 (2003).

https://doi.org/10.1023/A:1024738503198

[3] Ito K., Li H-L., Saito Y., Yamamoto T., Nishihara Y., Ujihira Y., Nomura K.: Free-volume study of ethylene - vinyl alcohol copolymer evaluated through positronium lifetime measurement. Journal of Radioanalytical and Nuclear Chemistry, 255, 437-441 (2003).

https://doi.org/10.1023/A:1022551525468

[4] Ito K., Saito Y., Yamamoto T., Ujihira Y., Nomura K.: Correlation study between oxygen permeability and free volume of ethylene-vinyl alcohol copolymer through positronium lifetime measurement. Macromolecules, 34, 6153-6155 (2001). https://doi.org/10.1021/ma001813a

[5] Moritani T., Iwasaki H.: Carbon-13 nuclear magnetic resonance study on sequence distribution and anomalous linkage in ethylene-vinyl alcohol copolymers. Macromolecules, 11, 1251-1259 (1978).

https://doi.org/10.1021/ma60066a036
[6] Takahashi M., Tashiro K., Amiya S.: Crystal structure of ethylene-vinyl alcohol copolymers. Macromolecules, 32, 5860-5871 (1999).

https://doi.org/10.1021/ma990521a

[7] Matsumoto T., Nakamae K., Ogoshi N., Kawasoe M., Oka H.: The crystallinity of ethylene-vinyl alcohol copolymers. Kobunshi Kagaku, 28, 610-617 (1971).

https://doi.org/10.1295/koron1944.28.610

[8] Bunn C. W., Peiser H. S.: Mixed crystal formation in high polymers. Nature, 159, 161-162 (1947).

https://doi.org/10.1038/159161b0

[9] Bunn C. W.: Molecular structure and the crystallinity of long-chain polymers. Journal of Applied Physics, 25, 820-825 (1954).

https://doi.org/10.1063/1.1721751

[10] Matsumoto T., Nakamae K., Oka H., Kawarai S., Ochiumi T.: The micro-structure of ethylene-vinyl alcohol copolymer. Sen'i Gakkaishi, 31, T152-T157 (1975). https://doi.org/10.2115/fiber.31.5 T152

[11] Nakamae K., Kameyama M., Matsumoto T.: Elastic moduli of the crystalline regions in the direction perpendicular to the chain axis of ethylene-vinyl alcohol copolymers. Polymer Engineering and Science, 19, 572-578 (1979).

https://doi.org/10.1002/pen.760190808

[12] Su Z., Zhao Y., Xu Y., Zhang X., Zhu S., Wang D., Wu J., Han C. C., Xu D.: Spectroscopic investigation of the polymorphism and side group location of ethylene copolymers. Macromolecules, 37, 3249-3256 (2004). https://doi.org/10.1021/ma0358576

[13] Su Z., Zhao Y., Xu Y., Zhang X., Zhu S., Wang D., Han C. C., Xu D.: Polymorphism and side group location of ethylene copolymers characterized by FTIR and NMR spectroscopy. Polymer, 45, 3577-3581 (2004).

https://doi.org/10.1016/j.polymer.2004.03.076

[14] Wunderlich B., Kashdan W. H.: Thermodynamics of crystalline linear high polymers. I. Comparison of the melting transitions of solution and melt-crystallized polyethylene. Journal of Polymer Science, 50, 71-78 (1961). https://doi.org/10.1002/pol.1961.1205015309

[15] Cerrada M. L., Pérez E., Pereña J. M., Benavente R.: Wide-angle X-ray diffraction study of the phase behavior of vinyl alcohol-ethylene copolymers. Macromolecules, 31, 2559-2564 (1998).

https://doi.org/10.1021/ma9705127

[16] VanderHart D. L., Simmons S., Gilman J. W.: Solidstate ${ }^{13} \mathrm{C}$ nuclear magnetic resonance spectroscopy of ethylene/vinyl alcohol copolymers: Morphological partitioning of hydroxyls. Polymer, 36, 4223-4232 (1995). https://doi.org/10.1016/0032-3861(95)92217-3

[17] Franco-Urquiza E., Santana O. O., Gámez-Pérez J., Martínez A. B., Maspoch M. L.: Influence of processing on the ethylene-vinyl alcohol (EVOH) properties: Application of the successive self-nucleation and annealing (SSA) technique. Express Polymer Letters, 4, 153-160 (2010).

https://doi.org/10.3144/expresspolymlett.2010.20 
[18] Franco-Urquiza E. A., Santana O., Maspoch M. L.: Influence of the melt extrusion process on the mechanical behavior and the thermal properties of ethylene vinyl alcohol copolymer by applying the successive self-nucleation and annealing thermal fractionation. Fibers and Polymers, 22, 1822-1829 (2021).

https://doi.org/10.1007/s12221-021-0386-2

[19] Müller A. J., Hernández Z. H., Arnal M. L., Sánchez J. J.: Successive self-nucleation/annealing (SSA): A novel technique to study molecular segregation during crystallization. Polymer Bulletin, 39, 465-472 (1997). https://doi.org/10.1007/s002890050174

[20] Su G., Zhou T., Liu X., Zhang J., Bao J., Zhang A.: Two-dimensional correlation infrared spectroscopy reveals the detailed molecular movements during the crystallization of poly(ethylene- $c o$-vinyl alcohol). RSC Advances, 5, 84729-84745 (2015). https://doi.org/10.1039/C5RA13486B

[21] Kalfoglou N. K., Samios C. K., Papadopoulou C. P.: Compatibilization of poly(ethylene-co-vinyl alcohol) $(\mathrm{EVOH})$ and EVOH-HDPE blends: Structure and properties. Journal of Applied Polymer Science, 68, 589-596 (1998).

https://doi.org/10.1002/(SICI)10974628(19980425)68:4<589::AID-APP10>3.0.CO;2-N

[22] De Petris S., Laurienzo P., Malinconico M., Pracella M., Zendron M.: Study of blends of nylon 6 with EVOH and carboxyl-modified EVOH and a preliminary approach to films for packaging applications. Journal of Applied Polymer Science, 68, 637-648 (1998).

https://doi.org/10.1002/(SICI)10974628(19980425)68:4<637::AID-APP15>3.0.CO;2-O

[23] Vannini M., Marchese P., Celli A., Lorenzetti C.: Strategy to modify the crystallization behavior of EVOH32 through interactions with low-molecular-weight molecules. Industrial and Engineering Chemistry Research, 55, 3517-3524 (2016).

https://doi.org/10.1021/acs.iecr.5b04191

[24] Péter Zs., Kenyó Cs., Renner K., Kröhnke C., Pukánszky B.: Decreased oxygen permeability of EVOH through molecular interactions. Express Polymer Letters, 8, 756-766 (2014).

https://doi.org/10.3144/expresspolymlett.2014.78

[25] Luzi F., Torre L., Puglia D.: Antioxidant packaging films based on ethylene vinyl alcohol copolymer (EVOH) and caffeic acid. Molecules, 25, 3953 (2020). https://doi.org/10.3390/molecules25173953

[26] Sánchez-Chaves M., Ruiz C., Cerrada M. L., FernándezGarcía M.: Novel glycopolymers containing aminosaccharide pendant groups by chemical modification of ethylene-vinyl alcohol copolymers. Polymer, 49, 28012807 (2008).

https://doi.org/10.1016/j.polymer.2008.04.047

[27] Aktzi N., Nir Y., Wang D., Narkis M., Siegmann A.: EVOH/clay nanocomposites produced by melt processing. Polymer Composites, 22, 710-720 (2001). https://doi.org/10.1002/pc.10573
[28] Orr M. P., Sonekan A., Shofner M. L.: Effect of processing method on cellulose nanocrystal/polyethyleneco-vinyl alcohol composites. Polymer Engineering and Science, 60, 2979-2990 (2020).

https://doi.org/10.1002/pen.25527

[29] Wang P., Wang H., Liu J., Wang P., Jiang S., Li X., Jiang S.: Montmorillonite@chitosan-poly(ethylene oxide) nanofibrous membrane enhancing poly(vinyl alcoholco-ethylene) composite film. Carbohydrate Polymers, 181, 885-892 (2018).

https://doi.org/10.1016/j.carbpol.2017.11.063

[30] David G., Pérez J.: Combined sampler robot and highperformance liquid chromatography: A fully automated system for biological small-angle X-ray scattering experiments at the Synchrotron SOLEIL SWING beamline. Journal of Applied Crystallography, 42, 892-900 (2009). https://doi.org/10.1107/S0021889809029288

[31] Blundell D. J.: On the interpretation of multiple melting peaks in poly(ether ether ketone). Polymer, 28, 22482251 (1987).

https://doi.org/10.1016/0032-3861(87)90382-X

[32] Marand H., Alizadeh A., Farmer R., Desai R., Velikov V.: Influence of structural and topological constraints on the crystallization and melting behavior of polymers. 2. Poly(arylene ether ether ketone). Macromolecules, 33, 3392-3403 (2000). https://doi.org/10.1021/ma9913562

[33] Alamo R. G., Kim M-H., Galante M. J., Isasi J. R., Mandelkern L.: Structural and kinetic factors governing the formation of the $\gamma$ polymorph of isotactic polypropylene. Macromolecules, 32, 4050-4064 (1999). https://doi.org/10.1021/ma981849r

[34] Alamo R. G., Brown G. M., Mandelkern L., Lehtinen A., Paukkeri R.: A morphological study of a highly structurally regular isotactic poly(propylene) fraction. Polymer, 40, 3933-3944 (1999). https://doi.org/10.1016/S0032-3861(98)00613-2

[35] Pan P., Kai W., Zhu B., Dong T., Inoue Y.: Polymorphous crystallization and multiple melting behavior of poly(L-lactide): Molecular weight dependence. Macromolecules, 40, 6898-6905 (2007). https://doi.org/10.1021/ma071258d

[36] Wang X., Zhou J., Li L.: Multiple melting behavior of poly(butylene succinate). European Polymer Journal, 43, 3163-3170 (2007). https://doi.org/10.1016/j.eurpolymj.2007.05.013

[37] Schick C., Androsch R.: The origin of annealing peaks in semicrystalline polymers: Enthalpy recovery or melting? Macromolecules, 53, 8751-8756 (2020). https://doi.org/10.1021/acs.macromol.0c01879

[38] Jonas A. M., Russell T. P., Yoon D. Y.: Synchrotron X-ray scattering studies of crystallization of poly(ether-etherketone) from the glass and structural changes during subsequent heating-cooling processes. Macromolecules, 28, 8491-8503 (1995). https://doi.org/10.1021/ma00129a005 
[39] Okui N., Kawai T.: Crystallization of ethylene/vinylacetate random copolymers. Die Makromolekulare Chemie, 154, 161-176 (1972).

https://doi.org/10.1002/macp.1972.021540115

[40] Crist B., Howard P. R.: Crystallization and melting of model ethylene-butene copolymers. Macromolecules, 32, 3057-3067 (1999).

https://oi.org/10.1021/ma9816362

[41] Pérez E., Benavente R., Bello A., Pereña J. M., Zucchi D., Sacchi M. C.: Crystallization behaviour of fractions of a copolymer of propene and 1-hexane. Polymer, 38, 5411-5418 (1997). https://doi.org/10.1016/S0032-3861(97)00064-5

[42] Lee B., Shin T. J., Lee S. W., Yoon J., Kim J., Ree M.: Secondary crystallization behavior of poly(ethylene isophthalate-co-terephthalate): Time-resolved smallangle X-ray scattering and calorimetry studies. Macromolecules, 37, 4174-4184 (2004).

https://doi.org/10.1021/ma0357321

[43] Fonseca C., Pereña J., Benavente R., Cerrada M. L., Bello A., Pérez E.: Microhardness and thermal study of the annealing effects in vinyl alcohol-ethylene copolymers. Polymer, 36, 1887-1892 (1995).

https://doi.org/10.1016/0032-3861(95)90936-V

[44] Ramakrishnan S.: Well-defined ethylene-vinyl alcohol copolymers via hydroboration: Control of composition and distribution of the hydroxyl groups on the polymer backbone. Macromolecules, 24, 3753-3759 (1991). https://doi.org/10.1021/ma00013a003

[45] Pérez E., Cerrada M. L., Vanderhart D. L.: Rapid determination of comonomer content, crystallinity, and long spacing by multiple-pulse proton NMR in ethylene-vinyl alcohol copolymers. Journal of Polymer Science Part B: Polymer Physics, 36, 2103-2109 (1998). https://doi.org/10.1002/(SICI)10990488(19980915)36:12<2103::AID-POLB9>3.0.CO;2-X

[46] López-Rubio A., Lagaron J. M., Giménez E., Cava D., Hernandez-Muñoz P., Yamamoto T., Gavara R.: Morphological alterations induced by temperature and humidity in ethylene-vinyl alcohol copolymers. Macromolecules, 36, 9467-9476 (2003).

https://doi.org/10.1021/ma035346j

[47] Stein R. S., Rhodes M. B.: Photographic light scattering by polyethylene films. Journal of Applied Physics, 31, 1873-1884 (1960). https://doi.org/10.1063/1.1735468

[48] Bartczak Z., Galeski A.: Homogeneous nucleation in polypropylene and its blends by small-angle light scattering. Polymer, 31, 2027-2038 (1990). https://doi.org/10.1016/0032-3861(90)90072-7

[49] Goderis B., Reynaers H., Koch M. H. J., Mathot V. B. F.: Use of SAXS and linear correlation functions for the determination of the crystallinity and morphology of semi-crystalline polymers. application to linear polyethylene. Journal of Polymer Science Part B: Polymer Physics, 37, 1715-1738 (1999).

https://doi.org/10.1002/(SICI)10990488(19990715)37:14<1715::AID-POLB15>3.0.CO;2-F
[50] Hoffman J. D., Davis G. T., Lauritzen J. I.: The rate of crystallization of linear polymers with chain folding. in 'Treatise on solid state chemistry' (ed.: Hannay, N. B.), Springer, Boston, 497-614 (1976).

https://doi.org/10.1007/978-1-4684-2664-9 7

[51] Alvarez V. A., Kenny J. M., Vázquez A.: Isothermal crystallization of poly(vinyl alcohol-co-ethylene). Journal of Applied Polymer Science, 89, 1071-1077 (2003). https://doi.org/10.1002/app.12255

[52] Cheng S. Z. D., Wunderlich B.: Glass transition and melting behavior of poly(ethylene 2,6-naphthalenedicarboxylate). Macromolecules, 21, 789-797 (1988).

https://doi.org/10.1021/ma00181a040

[53] Liu T., Petermann J.: Multiple melting behavior in isothermally cold-crystallized isotactic polystyrene. Polymer, 42, 6453-6461 (2001).

https://doi.org/10.1016/S0032-3861(01)00173-2

[54] Glotin M., Mandelkern L.: Crystalline morphology of isothermally crystallized branched polyethylene. Macromolecules, 14, 1394-1404 (1981).

https://doi.org/10.1021/ma50006a049

[55] Mandelkern L., Glotin M., Benson R. A.: Supermolecular structure and thermodynamic properties of linear and branched polyethylenes under rapid crystallization conditions. Macromolecules, 14, 22-34 (1981).

https://doi.org/10.1021/ma50002a004

[56] Stein R. S.: Some scattering studies of polymer microstructures, surfaces, and interfaces. Pure and Applied Chemistry, 63, 941-950 (1991).

https://doi.org/10.1351/pac199163070941

[57] Crist B., Williams D. N.: Crystallization and melting of model ethylene-butene random copolymers: Thermal studies. Journal of Macromolecular Science Part B, Physics, 39, 1-13 (2000).

https://doi.org/10.1081/MB-100100367

[58] Alizadeh A., Richardson L., Xu J., McCartney S., Marand H., Cheung Y. W., Chum S.: Influence of structural and topological constraints on the crystallization and melting behavior of polymers. 1. Ethylene/1-octene copolymers. Macromolecules, 32, 6221-6235 (1999). https://doi.org/10.1021/ma990669u

[59] Cheng S. Z. D., Cao M. Y., Wunderlich B.: Glass transition and melting behavior of poly(oxy-1,4-phenyleneoxy-1,4-phenylenecarbonyl-1,4-phenylene) (PEEK). Macromolecules, 19, 1868-1876 (1986).

https://doi.org/10.1021/ma00161a015

[60] Goderis B., Reynaers H., Koch M. H. J.: Primary and secondary crystallization in a homogeneous ethylene1-octene copolymer: Crystallinity heterogeneity studied by SAXS. Macromolecules, 35, 5840-5853 (2002). https://doi.org/10.1021/ma011749c

[61] Peppas N. A., Hansen P. J.: Crystallization kinetics of poly(vinyl alcohol). Journal of Applied Polymer Science, 27, 4787-4797 (1982).

https://doi.org/10.1002/app.1982.070271223 